\title{
The effects of epidural analgesia in normal labor
}

\author{
Pradeep Hosagoudar ${ }^{1, *}$, K R Vimala ${ }^{2}$, Uday Bhaskar ${ }^{3}$, Vallur Swetha Reddy ${ }^{4}$, L Krishna ${ }^{5}$ \\ ${ }^{1}$ Professor, Dept. of Anesthesiology, East Point College of Medical Sciences and Research Center, Bangalore, Karnataka, \\ ${ }^{2,5}$ Professor, ${ }^{3}$ Assistant Professor, ${ }^{4}$ Resident, ${ }^{3}$ Dept. of Anesthesiology, ${ }^{\mathbf{2}, \mathbf{4}}{ }^{5}$ Dept. of Obstetrics and Gynecology, P.E.S. Institute of \\ Medical Sciences and Research, Kuppam, Andhra Pradesh, India,
}

*Corresponding Author:

Email: drpaddy82@gmail.com

\begin{abstract}
Introduction: Labor pain is the most severe pain a women would experience and several treatment modalities have been adopted since decades. Labor analgesia using epidural technique is considered as the efficient and effective treatment options available. Parturients in India especially rural areas are less aware regarding labor analgesia using epidural technique.

Aim: To study the effects of labor analgesia using epidural technique in nulliparous women.

Materials and Methods: Sixty full term nulliparous women with singleton vertex pregnancy were made aware of labor analgesia using epidural technique and included, those willing were grouped epidural $(n=30)$, those not keen were grouped control( $n=30)$. In $1^{\text {st }}$ stage labor, parturients in epidural group received bupivacaine and fentanyl, whereas in control group received intramuscular Inj. tramadol, and Inj. pethidine if needed. Duration of $1^{\text {st }}$ and $2^{\text {nd }}$ stage labor, pain relief, maternal satisfaction, adverse effects, instrumental deliveries, $1^{\text {st }}$ and $5^{\text {th }}$ minute Apgar score and NICU admission were recorded.

Results: The mean duration of first stage labor was shorter $(\mathrm{p}=0.071)$ in epidural group $(250.17 \pm 106.33$ minutes $)$ compared with control group (302.0 \pm 111.99 minutes) and statistically insignificant prolongation $(\mathrm{p}=0.892)\left(18.73 \pm 6.82\right.$ minutes) of $2^{\text {nd }}$ stage labor as compared to control $(18.33 \pm 14.53$ minutes). Pain relief in epidural group was statistically significant $(\mathrm{p}<0.001)$. Instrumental delivery rate although higher in epidural group was statistically insignificant $(\mathrm{p}=1.00)$. The Apgar score at $1^{\mathrm{st}}(\mathrm{p}=0.306)$ and $5^{\text {th }}$ minutes ( $\mathrm{p}=1.00)$, NICU admission rate were statistically insignificant $(\mathrm{p}=0.143)$ between groups.

Conclusion: Labor epidural analgesia using Inj.bupivacaine and Inj.fentanyl provides good pain relief, safe for mother and baby. It does not affect labor duration, instrumental delivery rate or neonatal outcome.
\end{abstract}

Keywords: Labor analgesia, Epidural, Bupivacaine, Fentanyl, Labor stages, Apgar score, NICU admission.

\section{Introduction}

Pain of child birth is the most severe pain, women would experience in their lifetimes. American college of obstetricians and gynecologists (ACOG) suggested that if there is no medical contraindication, a parturient should receive labor analgesia and under no circumstance labor pain should be left untreated. ${ }^{1,2}$ Ensuring painless labor without significant adverse effects to mother, and safe fetal outcome should be the goal of labor analgesia. Among all modalities to treat labor pain, most effectively and efficiently used technique is epidural analgesia. ${ }^{3}$ There may be differences in perception of labor pain among parturients and hence different methods to treat pain have been used based on individual choice. ${ }^{4}$

Both non-pharmacologic and pharmacologic methods ${ }^{5}$ have been employed and labor analgesia by neuraxial technique, especially epidural technique is considered as gold standard. ${ }^{6}$ Several studies comparing labor analgesia by epidural technique versus use of nitrous oxide, opioids have concluded maternal pain scores to be lower with greater maternal satisfaction using epidural technique. ${ }^{6}$ With use of infusion pumps, labor epidural analgesia provides more predictable and uniform analgesia lessening chances of breakthrough pain and infection rate. Bupivacaine is a local anesthetic which is commonly used in labor analgesia by epidural technique, more recently levo-bupivacaine and ropivacaine have also been used. ${ }^{7}$ In the past couple of decades opioids such as fentanyl and sufentanil have been used in addition to local anesthetics, with advantage to use lesser concentrations of local anesthetic, better pain relief, better progression of both stages of labor and lesser chances of motor blockade. ${ }^{7}$ Epidural analgesia for labor has been actively practiced with increasing trend in western countries including United States, but in countries like India it is employed less frequently and used sporadically in few hospitals, ${ }^{4}$ and most parturients are unaware of the treatment option. ${ }^{2}$

$A \delta$ and $C$ fibers of $T_{10}-L_{1}$ segments of spinal cord transmit pain of $1^{\text {st }}$ stage of labor and $\mathrm{S}_{2}-\mathrm{S}_{4}$ segments in $2^{\text {nd }}$ stage of labor and goal is to block these nerves for pain free labor. ${ }^{6}$

\section{Aims and Objectives}

To study effect of labor epidural analgesic technique using bupivacaine and fentanyl in normal labor. Primary objectives included management of labor pain, duration of $1^{\text {st }}$ and $2^{\text {nd }}$ stage of labor, maternal satisfaction with birth experience and adverse effects associated with the use of epidural technique for management of labor pain. Secondary objectives included Apgar scores of newborn at $1^{\text {st }}$ and $5^{\text {th }}$ minutes and mode of delivery by either spontaneous, instrumentation techniques. 


\section{Materials and Methods}

This was a prospective, clinical, comparative observational study, undertaken in association with anesthesiologists and obstetricians after obtaining Ethics committee approval at P.E.S. Institute of Medical Sciences and Research, Kuppam. After obtaining written and informed consent, 60 parturients in labor were included in our study and divided into two equal groups. Parturients $(n=30)$ who were willing to opt epidural technique were categorized to Group-I (epidural group) and those not interested were categorized to Group-II (control group) $(\mathrm{n}=30)$.

Inclusion criteria included, nulliparous women with singleton vertex presentation in gestational age between 37 - 41 weeks, hemoglobin $\geq 9 \mathrm{gm} \%$, American Society of Anesthesiologists (ASA) physical status I or II, in active phase of labor (cervical dilatation $>4 \mathrm{~cm}$ ) with good rate pattern of fetal heart insisting for epidural analgesia. Following were criteria for exclusion- contraindications to epidural technique e.g.- bleeding diathesis or coagulopathy abnormality, infection at epidural injection site, anatomical abnormalities of spine, neurologic/neuromuscular diseases, allergy to local anesthetics etc, ASA status $>$ II, gestational age of $<37$ weeks or $>42$ weeks, cephalo-pelvic disproportion, cervical dilatation $\langle 4 \mathrm{~cm}$, multiparity, pregnancy with cardiac or respiratory diseases, psychiatric illness, evidence of abnormal fetal heart rate pattern, medical disorders complicating pregnancy like diabetes, hypertension etc., sepsis, fetal malformation or growth retarded fetus, fever of more than $38^{\circ} \mathrm{C}$. Parturients who underwent caesarean section for any indication were excluded from the study.

All parturients were consulted by anesthesiologist and underwent clinical examination, examination of airway and spine before placing epidural catheter and were investigated for routine hemogram, PT-INR and APTT. Parturients who were willing for epidural analgesia were counselled regarding nature of procedure, so as not to be apprehensive while performing procedure. Baseline vitals were recorded, and parturients in either group were connected to continuous electrocardiography (ECG), automated noninvasive blood pressure (NIBP), plethysmography $\left(\mathrm{SpO}_{2}\right)$ and fetal heart rate by cardiotocography and clinical examination throughout the course of labor. All participants received i.v. cannula (18G) and obstetric management was standardized in both groups including intravenous fluid management, use of medications, monitoring mother and fetus. Using cardiotocography, duration and frequency of uterine contractions were assessed. Labor progress was assessed every $2^{\text {nd }}$ hourly by pelvic examination and cervical dilation of atleast $1 \mathrm{~cm} /$ hour was expected. If necessitated, decision to undergo cesarean section was made according to indications of mother or baby.

Parturients in epidural group were preloaded with $500 \mathrm{ml}$ of lactated Ringer's solution and under strict aseptic precautions, in left lateral decubitus position $\mathrm{L}_{1}-$
$\mathrm{L}_{2}$ space was identified skin infiltrated with $3 \mathrm{ml}$ of $2 \%$ Inj.lignocaine. Using $18 \mathrm{G}$ epidural needle epidural space approached by loss of resistance to saline and $18 \mathrm{G}$ epidural catheter was threaded $5 \mathrm{cms}$ and secured appropriately and positioned supine with left uterine displacement. At $4 \mathrm{~cm}$ cervical dilatation and upon request for labor analgesia, $10 \mathrm{ml}$ of $0.125 \%$ Inj.bupivacaine with $100 \mu \mathrm{g}$ Inj.fentanyl added was injected to achieve sensory block around $\mathrm{T}_{10}$ level. Once epidural analgesia was established, continuous infusion of $0.125 \%$ Inj.bupivacaine and Inj.fentanyl $2 \mu \mathrm{g} / \mathrm{ml}$ at a rate of $5 \mathrm{ml} /$ hour was initiated to maintain labor analgesia. Boluses of $5 \mathrm{ml}$ of this drug preparation was administered for break through pain and infusion was set to higher rate in the range of 6-8 $\mathrm{ml} /$ hour. Hypotension (mean arterial pressure: $>20 \%$ reduction from baseline) was treated with additional left uterine displacement, maternal oxygen administration, i.v. fluid bolus, or i.v. ephedrine as indicated. The visual analogue pain scale (VAPS) [0-10 $\mathrm{mm}$ scale: $0=$ no pain, $10=$ worst pain ever] was measured at the peak of contractions before and 5, 10, 20, and $30 \mathrm{~min}$ after administration of epidural analgesia and then at hourly intervals. Level of sensory blockade to cold and modified Bromage Score were recorded after administering epidural drug preparation, and at 30 minutes and again at hourly intervals.

If any parturient in control group requested analgesia, $100 \mathrm{mg}$ of i.m. Inj.tramadol and Inj.pethidine $50 \mathrm{mg}$ i.m. on s.o.s. basis were administered. Any parturient in control group who was unable to bear pain and later was willing for epidural analgesia was also considered for the same, however they were excluded from the study.

Our primary outcome measures were pain relief, maternal satisfaction with birth experience, duration of $1^{\text {st }}$ stage of labor, duration of $2^{\text {nd }}$ stage of labor, adverse effects associated with use of epidural technique and medications for the management of labor pain. Secondary outcome measures were Apgar scores at $1^{\text {st }}$ and $5^{\text {th }}$ minutes. The study ended with extraction of baby vaginally by spontaneous, instrumental (forceps/vacuum) methods, or with decision to perform cesarean section irrespective of indication.

\section{Statistical Analysis}

The statistical software used in our study was SPSS 18.0, $\mathrm{R}$ environment version 3.2.2 for analysis of data, and Microsoft word and excel have been used to generate graphs, tables. Descriptive and inferential statistical analysis has been carried out in our study. Results on continuous measurements are presented on Mean \pm SD (Minimum-Maximum) and results on categorical measurements are presented in number (\%). The following assumptions on data were made:

1. Dependent variables should be normally distributed.

2. Samples drawn from the population should be random, cases of samples should be independent. 
Student $t$ test (two tailed, independent) has been used to find the significance of study parameters on continuous scale between two groups (Inter group analysis) on metric parameters. Leven 1s test to assess the homogeneity of variance. Chi-square/ Fisher Exact test has been used to find the significance of study parameters on categorical scale between two or more groups, non-parametric setting for qualitative data analysis. Fisher Exact test was used when cell samples were very small. 'p' value of $<0.05$ was considered to be significant, values of $0.01<\mathrm{p} \leq 0.05$ as moderately significant and $\mathrm{p} \leq 0.01$ as highly significant.

\section{Results}

All parturients who were enrolled, chose to remain in same group till the end of study and none of them were initially included and later excluded secondary to any reason. Parturients were similar demographically with respect to mean age, height and weight, and obstetrically with respect to gestational age (Table 1), and showed no statistical significance. Their age varied between 18 and 32 years (Mean $\pm \mathrm{SD}=21.73 \pm 3.20$ ) in epidural group and 18 and 33 years $(M e a n \pm S D=21.53 \pm 3.01)$ in control group (Table 1). Their gestational age varied between $37-41$ weeks $(39.19 \pm 1.01)$ in epidural group and between 38-40 weeks in control group $(39.56 \pm 0.81)$ (Table 1, Fig. 1).

The mean duration from the time of $4 \mathrm{~cm}$ dilation of cervix to full dilatation (active stage of labor) was shorter in epidural group $(250.17 \pm 106.33 \mathrm{~min})$ compared with control group $(302.00 \pm 111.99 \mathrm{~min})$ but it was statistically insignificant $(\mathrm{p}=0.071)$ (Table 2, Fig. 2). There was no statistically significant difference $(p=0.892)$ in mean duration of second stage of labor in epidural group (18.73 $\pm 6.82 \mathrm{~min})$ compared with control group (18.33 $\pm 14.53 \mathrm{~min}$ ) (Table 2, Fig. 2).

Pain score of the patient varied between 1-3 in epidural group and between 4-10 in control group $(\mathrm{p}<0.001)$ (Table 3, Fig. 3). Patient satisfaction was good to excellent with epidural group (Table 4). Epidural infusion with $0.125 \%$ Inj.bupivacaine and Inj.fentanyl 2 $\mu \mathrm{g} / \mathrm{ml}$ resulted in effective analgesia and VAPS was 0-3 within 5 minutes of injection and then maintained mostly at same level when checked at hourly interval till the end of study. The epidural infusion was maintained at a rate of $5 \mathrm{ml} /$ hour. Four patients requested supplementary analgesia in epidural group and bolus dose $(5 \mathrm{ml})$ was administered. Two patients in epidural group developed motor block (6.7\% of patients had modified Bromage score-3) and resolved after temporary discontinuation of epidural infusion $(\mathrm{p}=0.492)$. After extraction of baby, epidural infusion was discontinued and sensory blockade was reversed within 1 hour after delivery of baby. No other adverse effects were noted with regard to epidural procedure, or the medications used.

Epidural analgesia using $0.125 \%$ Inj.bupivacaine and Inj.fentanyl $2 \mu \mathrm{g} / \mathrm{ml}$ during did not significantly prolong first or second stages of labor $(\mathrm{p}=0.071$ and 0.892 respectively). Instrumental deliveries (forceps/vacuum-assisted) conducted were statistically insignificant between the groups $(\mathrm{p}=1.00)$ (Table 2). Neonates with Apgar scores below 7 at $1^{\text {st }}$ and $5^{\text {th }}$ minutes were statistically insignificant (Table 5, Fig. 4). Birth weight of babies varied between $2.2-3.7 \mathrm{~kg}$ $(2.85 \pm 0.39)$ in epidural group and between $2.2-3.8 \mathrm{~kg}$ $(2.75 \pm 0.38)$ in control group and was statistically insignificant ( $\mathrm{p}=0.295$ ) (Fig. 5). The rate of neonatal ICU admissions was lower in epidural group (13.3\%) compared to control group (16.7\%) $(\mathrm{p}=0.143)($ Table 6).

Table 1: Patient characteristics. Data are mean (range) or Mean \pm SD

\begin{tabular}{|l|c|c|c|}
\hline \multicolumn{1}{|c|}{ Patient data } & Group I $(\mathbf{n = 3 0})$ & Group II $(\mathbf{n}=\mathbf{3 0})$ & p value \\
\hline Age (years) & $21.73 \pm 3.20$ & $21.53 \pm 3.01$ & $0.804(\mathrm{~ns})$ \\
\hline Height $(\mathrm{cms})$ & $158.37 \pm 4.52$ & $156.98 \pm 5.96$ & $0.256(\mathrm{~ns})$ \\
\hline Weight $($ Kgs) & $59.18 \pm 2.16$ & $57.56 \pm 2.98$ & $0.312(\mathrm{~ns})$ \\
\hline $\begin{array}{l}\text { Gestational age } \\
\text { (weeks) }\end{array}$ & $39.19 \pm 1.01$ & $39.56 \pm 0.81$ & $0.116(\mathrm{~ns})$ \\
\hline
\end{tabular}

Student ' $\mathrm{t}$ ' test. Abbreviations: ${ }^{*} \mathrm{SD}=$ standard deviation, $\mathrm{p}<0.05$ significant, $\mathrm{ns}=$ statistically not significant.

Table 2: Comparison of first stage, second stage of labor and instrumental delivery between groups

\begin{tabular}{|l|c|c|c|c|}
\hline & Group I & Group II & Total & p value \\
\hline First Stage (minutes) & $250.17 \pm 106.33$ & $302.00 \pm 111.99$ & $276.08 \pm 111.7$ & $0.071(\mathrm{~ns})$ \\
\hline Second Stage (minutes) & $18.73 \pm 6.82$ & $18.33 \pm 14.53$ & $18.53 \pm 11.25$ & $0.892(\mathrm{~ns})$ \\
\hline Instrumental delivery & $2(6.7 \%)$ & $1(3.3 \%)$ & $3(5 \%)$ & $1.000(\mathrm{~ns})$ \\
\hline
\end{tabular}

Fisher Exact Test, $\mathrm{p}<0.05$ significant, $\mathrm{ns}=$ statistically not significant 
Table 3: Comparison of pain score between groups

\begin{tabular}{|l|c|c|c|}
\hline \multicolumn{1}{|c|}{ Pain Score } & Group I & Group II & Total \\
\hline 0 & $0(0 \%)$ & $0(0 \%)$ & $0(0 \%)$ \\
\hline $1-3$ & $30(100 \%)$ & $0(0 \%)$ & $30(50 \%)$ \\
\hline $4-6$ & $0(0 \%)$ & $25(83.3 \%)$ & $25(41.7 \%)$ \\
\hline $7-10$ & $0(0 \%)$ & $5(16.7 \%)$ & $5(8.3 \%)$ \\
\hline Total & $30(100 \%)$ & $30(100 \%)$ & $60(100 \%)$ \\
\hline
\end{tabular}

Fisher Exact Test, $\mathrm{p}<0.001$ (significant). $\mathrm{p}<0.05$ is significant

Table 4: Patient satisfaction in epidural group (Group I)

\begin{tabular}{|l|c|c|}
\hline Patient Satisfaction & No. of patients & \% \\
\hline Fair & 4 & 13.3 \\
\hline Good & 11 & 36.7 \\
\hline Excellent & 15 & 50.0 \\
\hline Total & 30 & 100.0 \\
\hline
\end{tabular}

Table 5: Comparison of Apgar scores at $1^{\text {st }}$ and $5^{\text {th }}$ minute between groups

\begin{tabular}{|c|c|c|c|c|}
\hline Apgar Score & $\begin{array}{c}\text { Group I } \\
(\mathbf{n}=\mathbf{3 0})\end{array}$ & $\begin{array}{c}\text { Group II } \\
(\mathbf{n}=\mathbf{3 0})\end{array}$ & $\begin{array}{c}\text { Total } \\
(n=60)\end{array}$ & p value \\
\hline \multicolumn{5}{|l|}{$1^{\text {st }}$ minute } \\
\hline $1-3$ & $2(6.7 \%)$ & $0(0 \%)$ & $2(3.3 \%)$ & \multirow{3}{*}{$0.306(\mathrm{~ns})$} \\
\hline $4-6$ & $3(10 \%)$ & $6(20 \%)$ & $9(15 \%)$ & \\
\hline $7-10$ & $25(83.3 \%)$ & $24(80 \%)$ & $49(81.7 \%)$ & \\
\hline \multicolumn{5}{|l|}{$5^{\text {th }}$ minute } \\
\hline $1-3$ & $0(0 \%)$ & $0(0 \%)$ & $0(0 \%)$ & \multirow{3}{*}{$1.00(\mathrm{~ns})$} \\
\hline $4-6$ & $2(6.7 \%)$ & $2(6.7 \%)$ & $4(6.7 \%)$ & \\
\hline $7-10$ & $28(93.3 \%)$ & $28(93.3 \%)$ & $56(93.3 \%)$ & \\
\hline
\end{tabular}

Fisher Exact Test, $\mathrm{p}<0.05$ significant, $\mathrm{ns}=$ statistically not significant

Table 6: Comparison of NICU admission between groups.

\begin{tabular}{|l|c|c|c|}
\hline \multicolumn{1}{|c|}{ NICU } & Group I & Group II & Total \\
\hline Nil & $26(86.7 \%)$ & $25(83.3 \%)$ & $51(85 \%)$ \\
\hline Perinatal A & $3(10 \%)$ & $0(0 \%)$ & $3(5 \%)$ \\
\hline Perinatal B & $1(3.3 \%)$ & $2(6.7 \%)$ & $3(5 \%)$ \\
\hline Respiratory & $0(0 \%)$ & $3(10 \%)$ & $3(5 \%)$ \\
\hline Total & $30(100 \%)$ & $30(100 \%)$ & $60(100 \%)$ \\
\hline
\end{tabular}

Fisher Exact Test, $\mathrm{p}=0.143(\mathrm{~ns}) . \mathrm{p}<0.05$ significant.

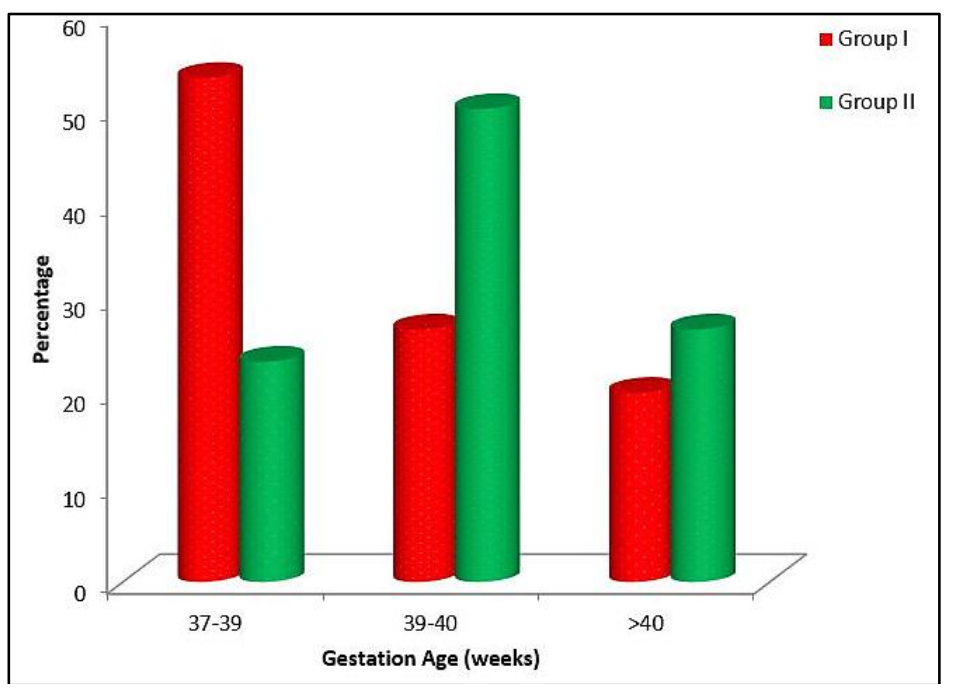

Fig. 1: Comparison of gestational age between the groups 


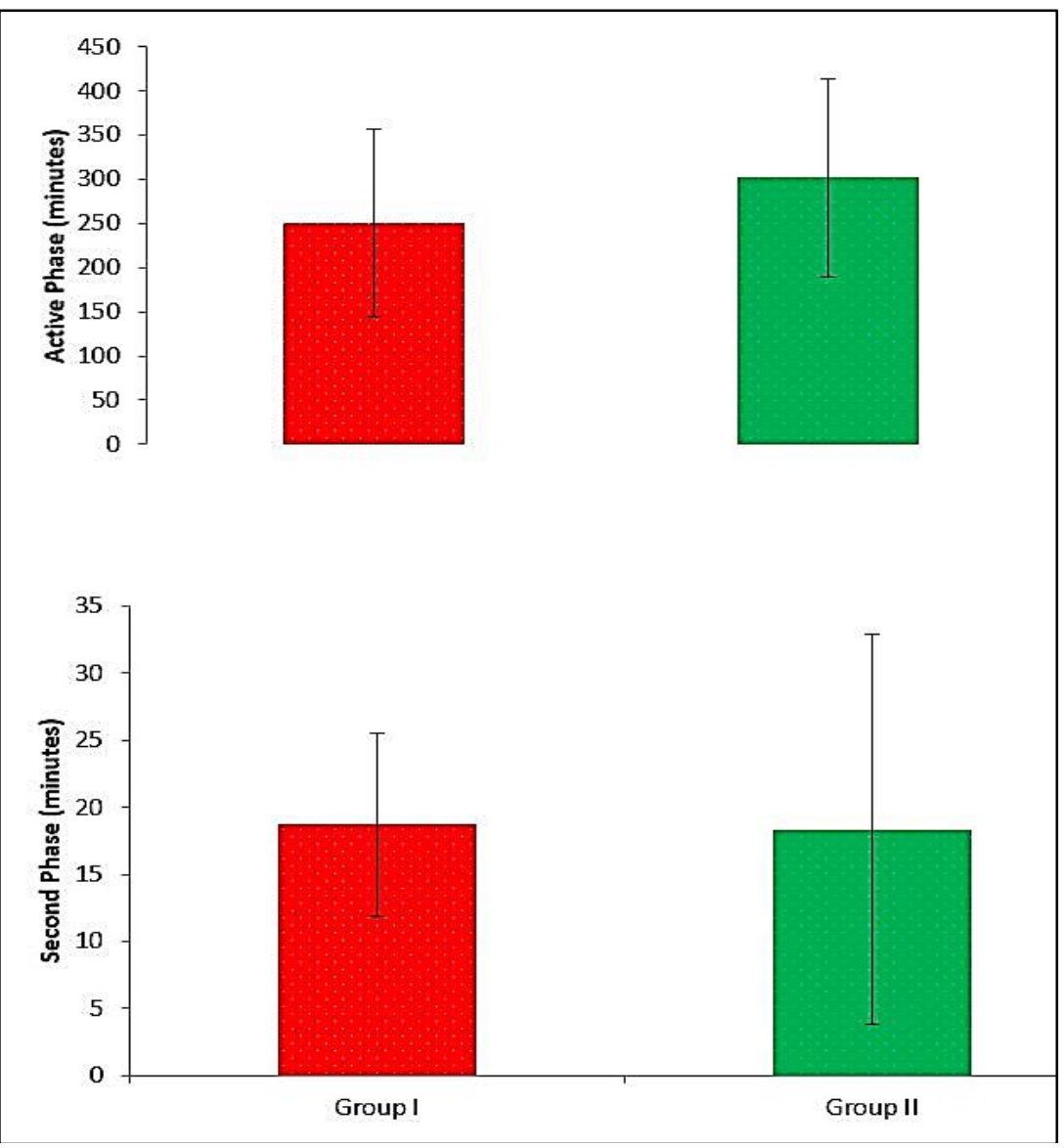

Fig. 2: Comparison of duration of first and stage of labor between the two groups

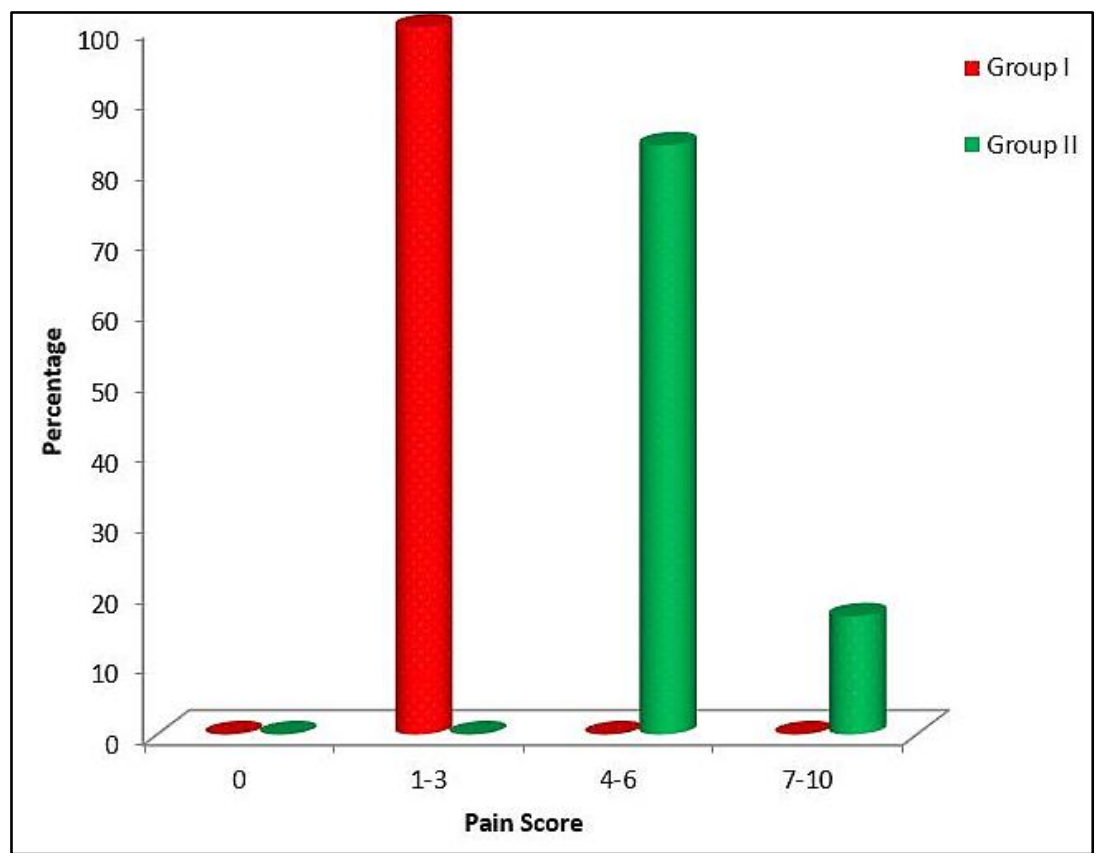

Fig. 3: Comparison of pain scores between the groups 


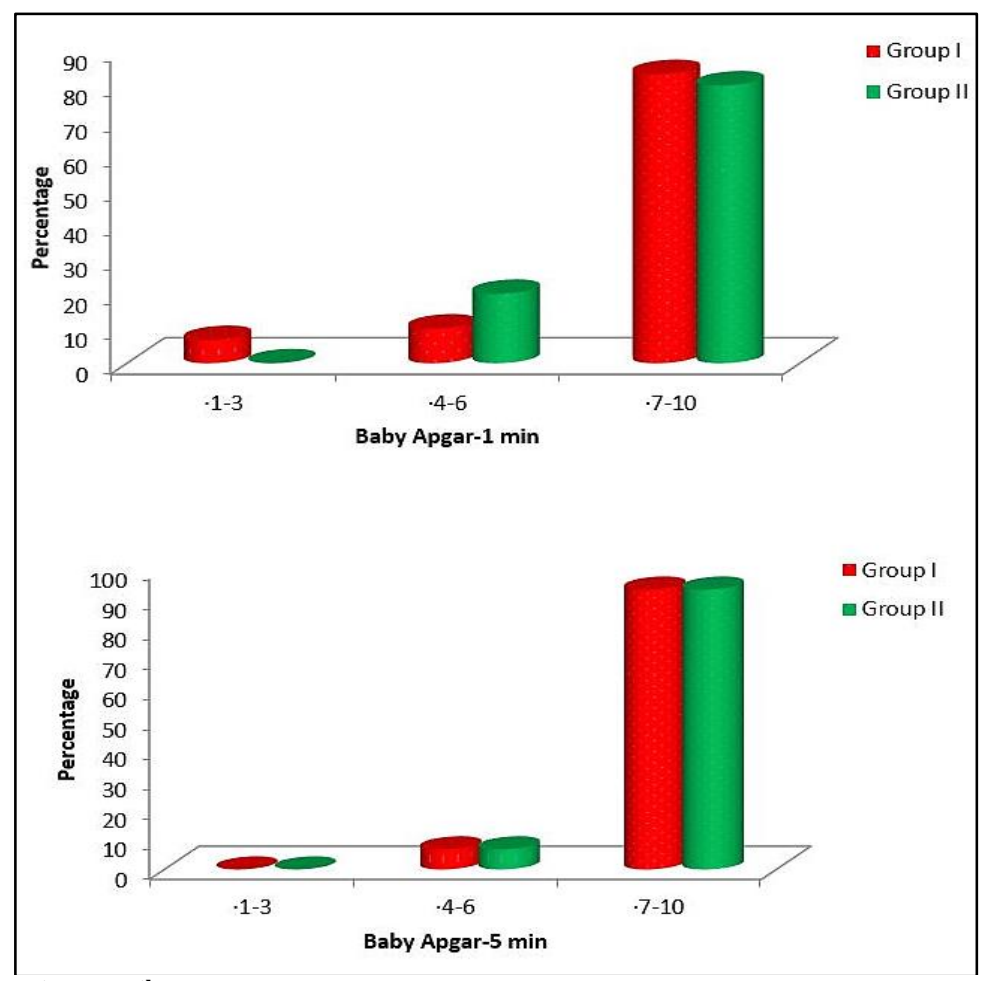

Fig. 4: Comparison of $1^{\text {st }}$ and $5^{\text {th }}$ minute Apgar score between the two groups

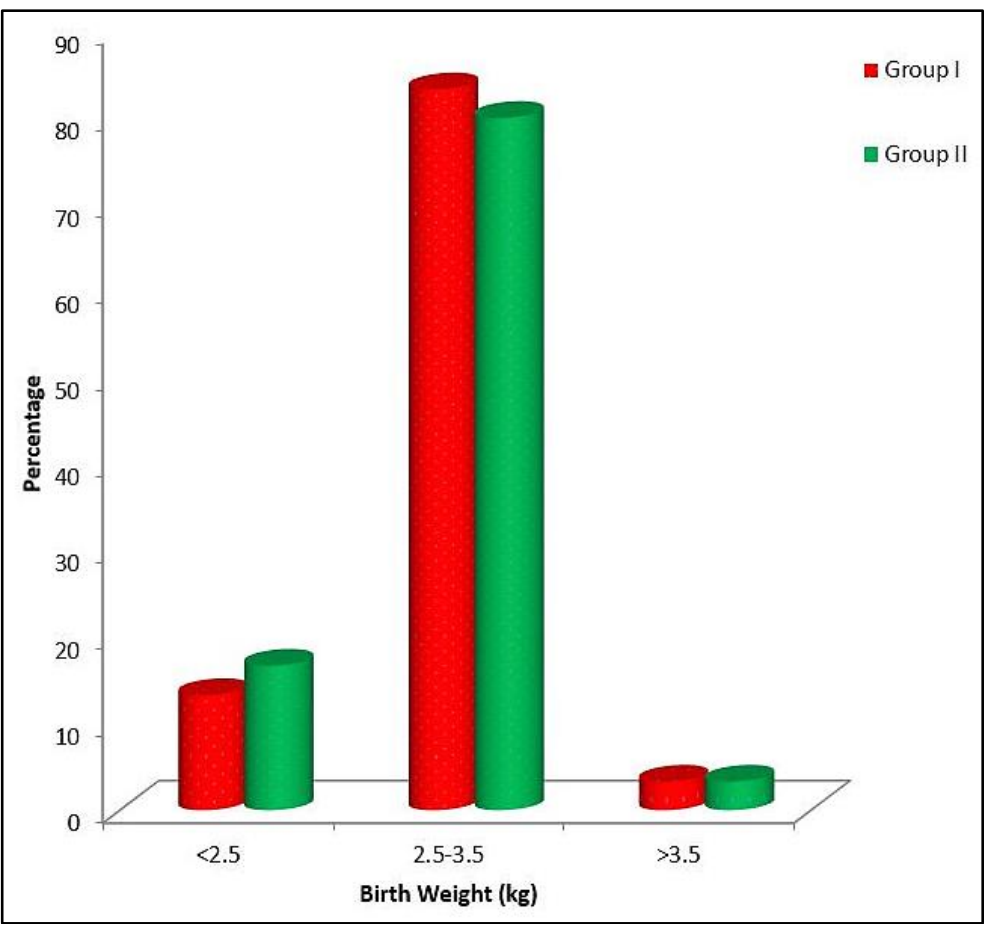

Fig. 5: Comparison of birth weight of babies between the two groups

\section{Discussion}

Ideal labor analgesic technique should be safe for both mother and baby, easy to administer, should have consistent, predictable, rapid onset of action through both $1^{\text {st }}$ and $2^{\text {nd }}$ stages of labor without prolongation, devoid of motor blockade- retaining maternal efforts to expel the baby and able to facilitate cesarean section delivery if necessitated. ${ }^{7}$

Nonpharmacological methods for labor analgesia include transcutaneous electrical nerve stimulation, touch and massage, water bath, intradermal sterile water injections, acupuncture, hypnosis and although helpful do not ensure satisfactory pain relief. ${ }^{8}$ 
Pharmacological methods which are used for labor analgesia include parenteral opioids, ${ }^{9}, 10$ Entonox, Sevox, combined spinal and epidural technique (CSE), continuous epidural analgesia technique., ${ }^{2,6}$ Labor analgesia using epidural technique is currently the gold standard technique among all options available. ${ }^{11}$ CSE and continuous labor epidural techniques have advantages of being reliable and rapid onset of action, providing consistent and satisfactory pain relief. ${ }^{12}$ Studies using low concentrations of local anesthetics in continuous epidural technique have advantages of least motor blockade and lesser quantities of local anesthetics used. ${ }^{13,14}$ Maintenance of pain free intervals in labor analgesia while using epidural technique is by intermittent manual boluses or through patientcontrolled analgesia or infusion pumps. ${ }^{15}$

ACOG recommends that in nulliparous women when feasible to withhold epidural analgesia until cervix is $4 \mathrm{cms}$ dilated that is until active stage of $1^{\text {st }}$ stage of labor sets in. In our study, epidural analgesia was initiated once active stage of labor was established. ${ }^{16}$

Use of parenteral opioids alone, for labor analgesia has resulted in delay in $1^{\text {st }}$ stage of labor when compared to epidural analgesia. ${ }^{8,9}$ In addition catecholamine release that happens as a response to active painful labor has inhibitory effects on uterine contractility thus prolonging $1^{\text {st }}$ stage of labor. With the use of epidural technique, blockade of conduction of pain through sympathetic fibers is ensured and thus decreased catecholamine release. Hence inhibitory effects of catecholamines on uterine contractility is reduced resulting in shortened $1^{\text {st }}$ stage of labor and faster cervical dilation. Our study correlates with studies done by Wong et $\mathrm{al}^{17}$ and Fyneface-Ogan et $\mathrm{al}^{18}$ where epidural analgesia shortened $1^{\text {st }}$ stage of labor.

Labor epidural analgesia has been known to prolong $2^{\text {nd }}$ stage of labor happens more so when higher concentrations or dose of local anesthetic agent is used. ${ }^{19}$ Pelvic floor muscles weakness is known to occur for the same reason and thus reducing the effective bearing down by the mother. ${ }^{20}$ This incidence is least when local anesthetics are used in low doses. ${ }^{21,22}$ In our study although prolongation of $2^{\text {nd }}$ stage of labor was noted in epidural group it was statistically insignificant. Addition of opioids like fentanyl and sufentanil in epidural analgesia further reduces requirement of local anesthetic agent and hence least motor blockade and $2^{\text {nd }}$ stage prolongation. ${ }^{19,21}$ In epidural group in our study, we used Inj.fentanyl as an additive in addition to Inj.bupivacaine to reduce epidural infusion rate.

The incidence of instrumental delivery increases with weakness of pelvic floor muscles and prolongation of $2^{\text {nd }}$ stage of labor, and this is considered as an important measure of outcome(instrumental delivery) in conduction of labor analgesia as it increases the risk of perineal trauma in mother and adverse out-comes of neonates in cases of difficult delivery. ${ }^{23}$ The 2011 Cochrane review showed a higher incidence of assisted vaginal deliveries with use of epidural analgesia when compared to non-epidural. ${ }^{24}$ But with use of dilute concentration of local anesthetic and addition of opioid to epidural infusion lowers the risk of instrumental deliveries. We used Inj.fentanyl in epidural infusion and our study showed statistically insignificant instrumental delivery rate in epidural group (6.7\%) compared to control group (3.3\%). Our findings are in contrast to a study which reported higher rate of instrumental deliveries in epidural group. ${ }^{25}$ Multiple confounding factors like technique of neuraxial analgesia, concentration of local anesthetic, method of maintenance of epidural analgesia, degree of analgesia during $2^{\text {nd }}$ stage of labor and obstetric reasons should be considered while interpreting the incidence of instrumental delivery. ${ }^{23}$ Our study shows findings similar to a study conducted by Anim-Somuah $\mathrm{M}$ et $\mathrm{al}^{24}$ and instrumental deliveries have declined over years as a result of changes undertaken in conduction of epidural analgesia and management of labor epidural. ${ }^{25,26}$

Our study demonstrated statistically insignificant difference in neonatal outcome as reflected by $1^{\text {st }}$ and $5^{\text {th }}$ minute Apgar scores and NICU admission rate and supports a meta-analysis of seven RCTs comparing low epidural infusion and parenteral opioids. ${ }^{25}$ Neonatal outcome was unsatisfactory when local anesthetics were used in high concentration. ${ }^{24}$ Our study also showed results similar to a study done using ropivacaine as a local anesthetic with respect to $1^{\text {st }}$ and $2^{\text {nd }}$ stage of labor, instrumental delivery and neonatal outcome. ${ }^{4}$

Maternal satisfaction with respect to birth experience was good to excellent using epidural technique. However, parturients in control group had moderate to severe pain and obviously were not satisfied, hence comparison was not undertaken. Cesarean delivery does not significantly increase with the use of neuraxial analgesia. ${ }^{24,27}$ In our study we noted shortened duration of $1^{\text {st }}$ stage of labor and insignificant prolongation of $2^{\text {nd }}$ stage of labor.

Lack of double blind methodology was the main drawback of our study. It was impossible to blind clinician or parturient to the assigned group, but strict obstetric protocols were followed and hence we would not expect biased results. Epidural analgesia is known to produce effective pain relief and may be criticized for control group not receiving it. Parturient in control group received Inj.tramadol, and Inj.pethidine as needed. Any parturient in control group who was not able to bear pain and later opted for epidural analgesia were also given this option but however such parturient was excluded from the study. In this way ethical issues were addressed.

\section{Conclusion}

Labor epidural technique using Inj.bupivacaine and Inj.fentanyl provides satisfactory analgesia and is safe for both mother and the baby, has good maternal satisfaction without significant increase in instrumental delivery rate. The duration of $1^{\text {st }}$ and $2^{\text {nd }}$ stage of labor 
were similar in both groups without statistically significant prolongation. The Apgar scores at $1^{\text {st }}$ and $5^{\text {th }}$ minutes and NICU admission rate were similar and thus safe for the baby.

\section{References}

1. Pain relief during labor. ACOG Committee opinion: Committee on obstetrics: Maternal and Fetal Medicine Number 118-January 1993. Int Journal Gynecol Obstet. 1993;42(1):73.

2. Sunil T Pandya. Labour analgesia: Recent advances. Indian Journal of Anaesthesia. 2010;54(5):400-8.

3. Srivastava U, Gupta A, Saxena S, Kumar A, Singh S, Saraswt N, Mishra R. Patient Controlled Epidural Analgesia during Labour: Effect of Addition of Background Infusion on Quality of Analgesia \& Maternal Satisfaction. Indian Journal of Anaesthesia. 2009;53(6):649-653.

4. Dipti Agrawal, Bela Makhija, Manjeet Arora, Arpana Haritwal, Pavan Gurha. The Effect of Epidural Analgesia on Labour, Mode of Delivery and Neonatal Outcome in Nullipara of India, 2011-2014. J Clin Diagn Res. 2014;8(10): OC03-6.

5. Silva M, Halpern SH. Epidural analgesia for labour: Current techniques. Local Reg Anesth. 2010;3:143-53.

6. Reena, Kasturi H. Bandyopadhyay, Mumtaz Afzal, Amiya K. Mishra, Abhijit Paul. Labor epidural analgesia: Past, present and future. Indian Journal of Pain. 2014;28(2):71-81.

7. J Sudarma Ranasinghe, David Birnbach. Current Status of Obstetric Anesthesia: Improving Satisfaction and Safety. Indian J Anesth. 2009;53(5):608-17.

8. Simkin PP, O'hara M. Nonpharmacologic relief of pain during labor: systemic reviews of five methods. Am J Obstet Gynecol. 2002;186(5):S131-59.

9. Rayburn W, Rathke A, Leuschen MP, Chleborad J, Weidner W. Fentanyl citrate analgesia during labor. Am J Obstet Gynecol. 1989;161(1):202-6.

10. Maduska AL, Haghassemali M. A double-blind comparison of butorphanol and meperidine in labor: maternal pain relief and effect on the newborn. Can Anaesth Soc J. 1978;25(5):398-404.

11. Hawkins JL. Epidural analgesia for Labour and delivery. N Engl J Med. 2010;362(16):1503-10.

12. Macarthur AJ. Gerard W. Ostheimer "What's New in Obstetric Anesthesia" Lecture. Anesthesiology. 2008;108(5):777-85.

13. Lacassie HJ, Habib AS, Lacassie HP, Columb MO. Motor blocking minimum local anesthetic concentrations of bupivacaine, levobupivacaine, and ropivacaine in labor. Reg Anesth Pain Med. 2007;32(4):323-9.

14. Boulier V, Gomis P, Lautner C, Visseaux H, Palot M, Malinovsky JM. Minimal concentration of ropivacaine and levobupivacaine with sufentanil for epidural analgesia in labour. Int J Obstet Anaesth. 2009;18(3):22630.

15. Leo S, Sia AT. Maintaining labour epidural analgesia: what is the best option? Curr Opin Anaesthesiol. 2008;21(3):263-9.

16. Goetzl LM. ACOG Practice Bulletin. Clinical Management Guidelines for Obstetrician-Gynecologists Number 36, July 2002. Obstetric analgesia and anesthesia. Obstet Gynecol. 2002;100(1):177-91.

17. Wong CA, Scavone BM, Peaceman AM. The risk of cesarean delivery with neuraxial analgesia given early versus late in labour. N Engl J Med. 2005;352(7):655-65.
18. Fyneface-Ogan S, Mato CN, Anya SE. Epidural anesthesia: views and outcomes of women in labour in a Nigerian hospital. Ann Afr Med. 2009;8(4):250-6.

19. Olofsson C, Ekblom A, Ekman-Ordeberg G, Irestedt L. Obstetric outcome following epidural analgesia with bupivacaine-adrenaline $0.25 \%$ or bupivacaine $0.125 \%$ with sufentanil: A prospective randomized controlled study in 1000 parturients. Acta Anaesthesiol Scand. 1998;42(3):284-92.

20. Thorburn J, Moir DD. Extradural analgesia: the influence of volume and concentration of bupivacaine on the mode of delivery, analgesic efficacy, and motor block. $\mathrm{Br} \mathrm{J}$ Anaesth. 1981;53(9):933-9.

21. Mousa WF, Al-Metwalli RR, Mostafa MM. Epidural analgesia during labor- $0.5 \%$ lidocaine with fentanyl vs $0.08 \%$ ropivacaine with fentanyl. Middle East J Anaesthesiol. 2010;20(4):521-7.

22. Nafisi S. Effects of epidural lidocaine analgesia on labor and delivery: A randomized, prospective, controlled trial. BMC Anesthesiology. 2006;6:15.

23. Cambic CR, Wong CA. Labour analgesia and obstetric outcomes. Br J Anaesth. 2010;105 Suppl. 1:i50-60.

24. Anim-Somuah M, Smyth RM, Jones L. Epidural versus non-epidural or no analgesia in labour. The Cochrane Database Systemic Review. 2011;12:CD000331.

25. Liu EH, Sia T. Rates of caesarean section and instrumental vaginal delivery in nulliparous women after low concentration epidural infusions or opioid analgesia: Systematic review. Br Med J. 2004;328(7453):1410-5.

26. Roberts CL, Algert CS, Douglas I, Tracy SK, Peat B. Trends in labour and birth inter-ventions among low-risk women in New South Wales. Aust N Z J Obstet Gynaecol. 2002;42(2):176-81.

27. Wong CA, Scavone BM, Peaceman AM. The risk of cesarean delivery with neuraxial analgesia given early versus late in labor. $N$ Engl J Med. 2005;352(7):655-65.

How to cite this article: Hosagoudar P, Vimala KR, Bhaskar U, Reddy VS, Krishna L. The effects of epidural analgesia in normal labor. Indian J Clin Anaesth. 2018;5(3):407-414. 